YING WANG, Ph.D.1,2

E-mail: 18101349051@163.com

BAO-MING HAN, Ph.D. ${ }^{3}$

E-mail: bmhan@bjtu.edu.cn

JIA-KANG WANG, Ph.D. ${ }^{4}$

(Corresponding author)

E-mail: wjksunny@126.com

1 School of Transportation and Logistics

Southwest Jiaotong University

No. 999, Xi'an Road, PI Du District,

Chengdu, Sichuan, China

2 Beijing National Railway Research \& Design Institute of Signal \& Communication Group Co., Ltd., Block B 1 South Road, Automobile Science Museum, Fengtai Science and Technology Park, Fengtai District, Beijing, China

${ }^{3}$ School of Traffic and Transportation, Beijing Jiaotong University, No. 3, Shangyuancun, Haidian District, Beijing, China

${ }^{4}$ Civil Aviation Management Institute of China, No. 3, Hua Jia Dong Road, Chaoyang District, Beijing, China
Transport Engineering Original Scientific Paper Submitted: 11 Sep. 2017 Accepted: 10 July 2018

\title{
A PASSENGER FLOW ROUTING MODEL FOR HIGH-SPEED RAILWAY NETWORK IN DIFFERENT TRANSPORTATION ORGANIZATION MODES
}

\begin{abstract}
Reasonable selection of passenger flow routes considering different transportation organization modes can meet the demands of adapting to large-scale high-speed railway networks and improving network efficiency. Passenger flow routing models are developed to find and optimize a set of passenger flow routes for a high-speed railway network considering different transportation organization modes. In this paper, we presented a new approach minimizing the operating costs, including traveling cost, cost of travel time differences between different lines, and penalties for the inter-line. The network was reconstructed to solve the directed graph with four nodes (node-in-up, node-in-down, nodes-outup, and nodes-out-down) indicating one station. To tackle our problem, we presented an integer non-linear programming model, and direct passenger demand was guaranteed owing to volume constraints. Binary variables were introduced to simplify the model, and the algorithm process was optimized. We suggested a global optimal algorithm by Lingo 11.0. Finally, the model was applied to a sub-network of the Northeast China railway system. Passenger flow routes were optimized and the transportation organization mode was discussed based on passenger volume, traveling distance, and infrastructure.
\end{abstract}

\section{KEY WORDS}

high-speed railway; train planning; transportation organization mode; passenger flow routing; integer non-linear programming model;

\section{INTRODUCTION}

High-speed railway (HSR) experiences a period of rapid development in China. The length of high-speed railways in service has reached 25,000 kilometers, ranked number one in the world in 2017, and it will increase to over 30,000 kilometers in 2020. High-speed railway has provided more convenient services for passengers. $30 \%$ of HSR lines operate at a maximum speed of $300 \mathrm{~km} / \mathrm{h}$ in China, depending on infrastructure conditions.

\subsection{Features analysis of a large-scale HSR network}

There are three typical features of a large-scale HSR network. The features will be elaborated by the example of HSR in China.

Larger scale network and longer operating mileage

Compared with Germany, France, Dutch, and Japan, China's high-speed railway network obviously has larger scale and longer operating mileage. China has the longest mileage and the largest scale high-speed railway network globally. The length of HSR in service has reached 25,000 kilometers, which is more than 60 percent of total HSR in the world. 


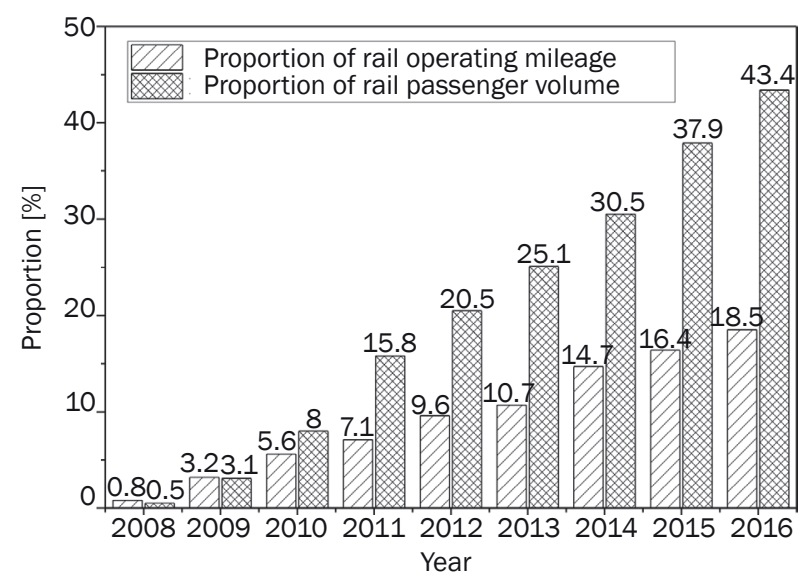

Figure 1 - High-speed railway change accounts for the proportion of railway passenger traffic volume and length of railways in operation

The HSR operating mileage and passenger volume are increasing year by year. High-speed railway takes $43.4 \%$ of the railway passenger volume with an operating mileage of $18.5 \%$ in China (Figure 1).

At the same time, there are HSR lines with a mileage of $1,000 \mathrm{~km}$ and above. For example, the length of the Beijing-Guangzhou high-speed railway is 2,298 kilometers, and it takes about 10 hours with a highspeed train from Beijing to Guangzhou.
Lower proportion of direct transportation

and unbalanced passenger volume per direction

Since China has a vast territory and varied terrain, passengers have created a pressing demand for direct transport. Statistics shows that direct passenger train services were provided to only 10\% OD pairs in 2016.

On the other hand, HSR provides lower train frequency for most OD pairs. $79.15 \%$ OD pairs are directly serviced with up to 5 trains, while $92.13 \%$ are directly serviced with up to 10 trains (Figure 2).

Unbalanced passenger volume by direction is widespread in large scale HSR networks. Figure 3 shows passenger volumes of several sections in the Baoji-Lanzhou HSR. There is a big passenger volume difference for some sections per directions.

\section{Complex passenger transportation in hubs}

There were 687 high-speed railway stations in China as of February 2017. Some cities have two or more high-speed railway stations. There is little difference in train classes between these stations. Connections through several stations in a single city add complexity to train operations. High-speed railway hubs have been formed with different scale and different features.

For example, there are seven main railway stations in Beijing: Beijing Railway Station, Beijing West Railway Station, Beijing South Railway Station, Beijing North

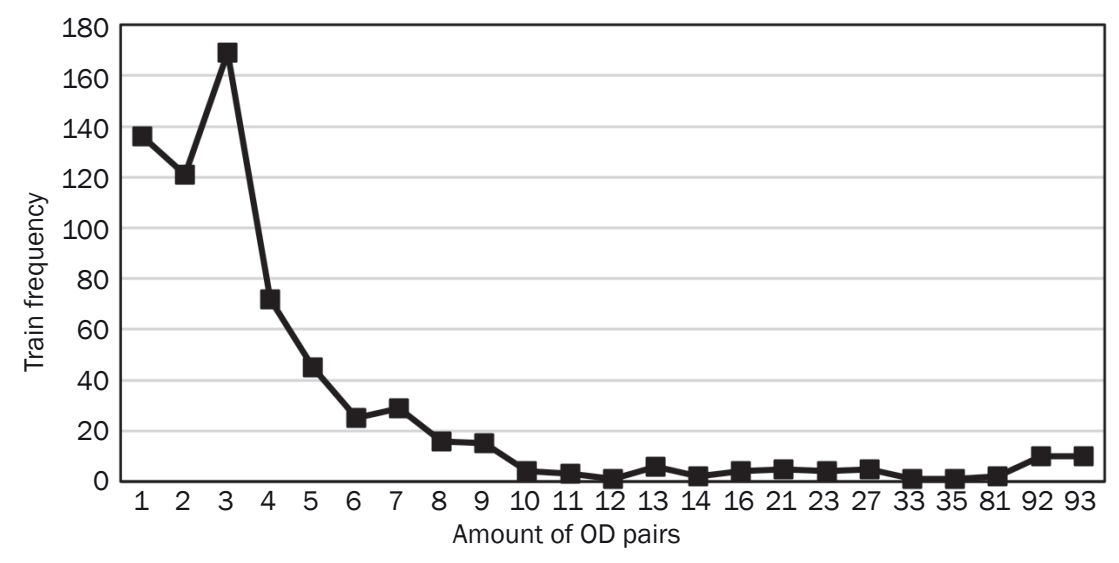

Figure 2 - The relationship of amount of OD pairs and train frequency

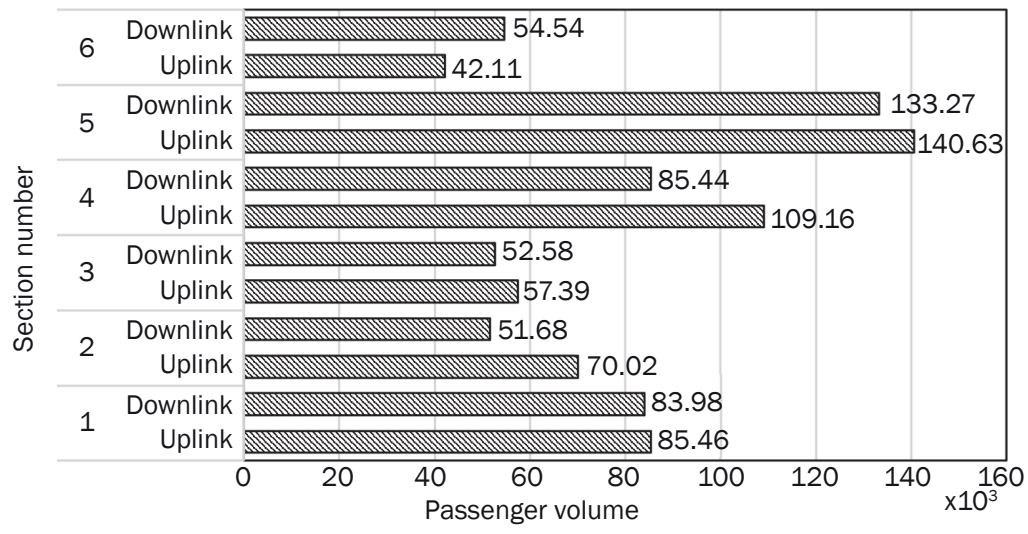

Figure 3 - Passenger volume of several sections per directions 
Railway Station, Fengtai Railway Station, Xinghuo Railway Station, and Tongzhou Railway Station. All of the trains at the Beijing South Railway Station are EMUs, while Beijing West Railway Station has 60\% EMUs. Other stations only have a few EMUs. Most of the stations cannot be connected to each other by railway.

More and more HSR stations will be constructed and operated in other cities with the development of the HSR network, such as Huizhou, Guangdong, which will have 9 stations.

\subsection{Transportation organization mode analysis of a large-scale HSR network}

These features have a big influence on the transportation organization mode of HSR, and the content of the transportation organization mode refers to direct or transfer, periodic or non-periodic, and intra-line or inter-line.

Definition of intra-line and inter-line. Intra-line: passengers' origin and destination belong to same line, and these passengers are serviced by one HSR line in a trip. As Figure 4 shows, the examples of intra-lines are 1-2-3-4-5-6-7, 1-11-12-13-14-8, and 7-8-9-10. Inter-line: passengers are serviced by two or more HSR lines in a trip, passengers' origin and destination belong to one or more lines. For example, 5-6-7-8, 5-6-78-14, 7-8-14-13-12-11-1, and so on (Figure 4).

There are vague transportation organization modes in HSR in China so far. The average path length of the Chinese high-speed railway network is $1,403.36 \mathrm{~km}$ (17.89 h) according to actual lines. Thicker lines mean higher frequency of trains (Figure 5). Only a few lines with shorter distance and large passenger volume have high-frequency trains and approximate periodic timetables. Most lines in the network have lower frequency trains. There is a large percentage of inter-line trains in the HSR network.

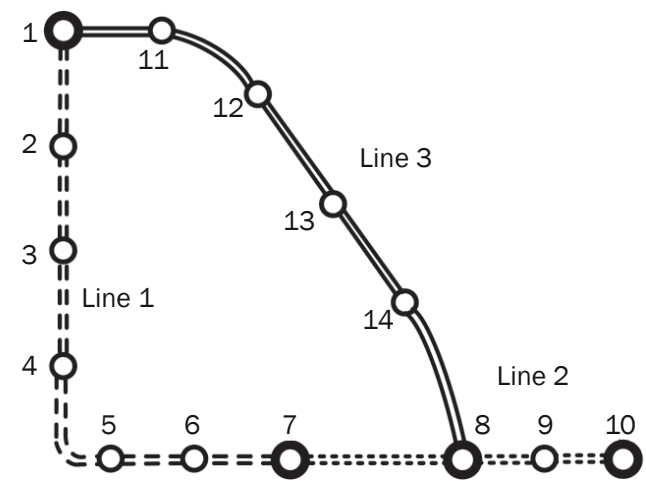

Figure 4 - Examples of intra-lines and inter-lines

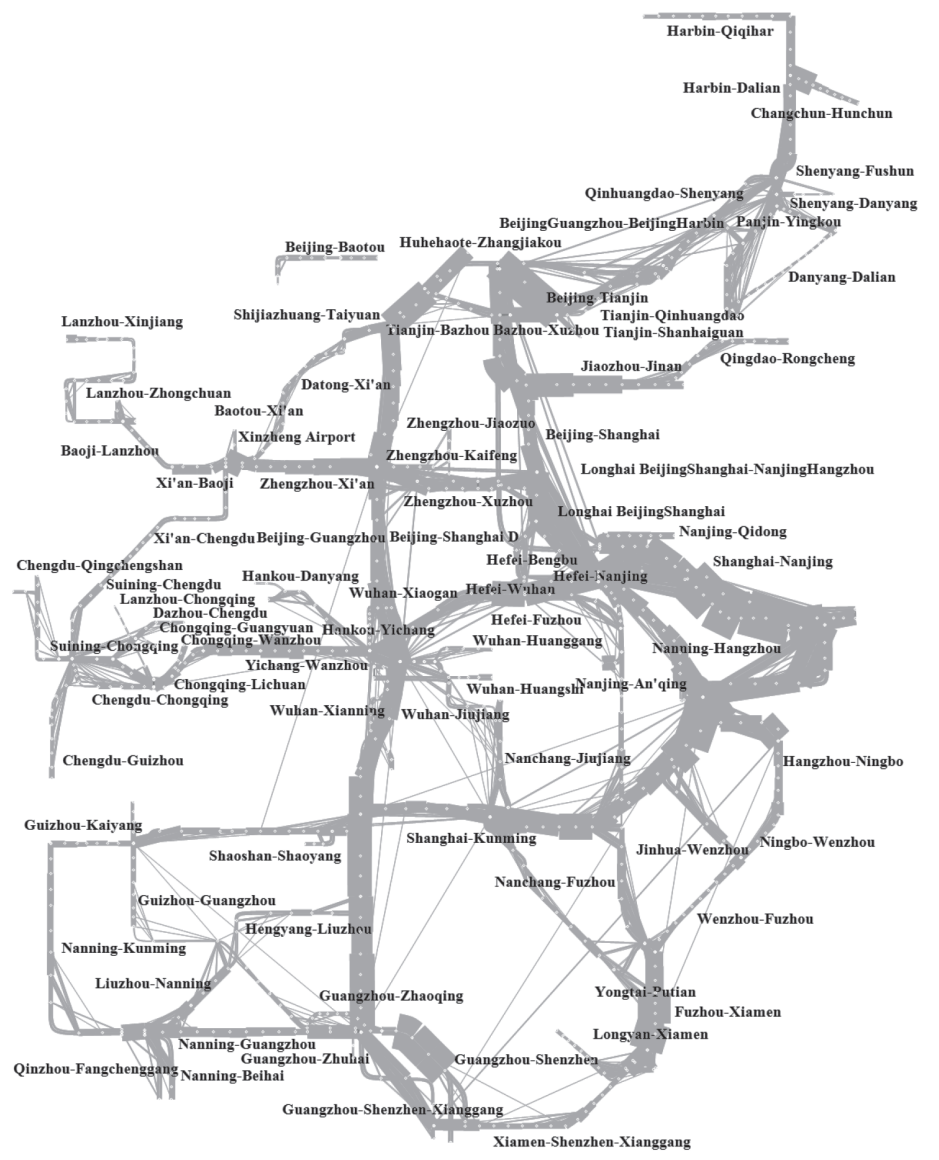

Figure 5 - Train service network of Chinese high-speed railway (2016) 


\subsection{Relevant research}

Previous studies introduced some relevant methods detailing the transportation organization modes of HSR networks. They are classified into three categories: (1) transportation organization mode for specific high-speed lines, (2) passenger flow routing programming of high-speed railway network, and (3) passenger routing in line planning and timetabling.

Studies on transportation organization mode for specific high-speed lines. Many researchers explored the transportation organization modes of some typical high-speed lines, such as Shijiazhuang-Taiyuan HSR [1], Beijing-Shanghai HSR [2], Beijing-Tianjin HSR [3]. The inter-line mode, periodic or non-periodic, was discussed based on operation experience. There were three levels of rail services in the Netherlands' HSR [4]: IC, IR, and AR, which provided varied and fixed services based on a classified station system. A lot of features and experiences regarding the transportation organization modes of European [5] and Japanese [6-7] high-speed trains have been reported, including designing of train stops, train connections and transfers, combination modes of through trains and transfer trains via timetable mining. Train operation models were constructed to solve the relationship of transfer mode and nonstop mode [8-9] while determining the proportion of different train classes.

Passenger flow routing in HSR network. In previous studies, the object of passenger flow routing model would be minimizing train traveling time or maximizing the number of direct passengers. Enormous research efforts go into selecting the shortest path. Dijkstra's algorithm was used with a physical traffic network [913]. A model was put forward to pair nodes using an undirected graph, and undirected passenger routing was solved by a linear model which maximizes the number of direct passengers [14]. Passenger routing was transferred into a combinatorial optimization problem. The cross-entropy method was used to solve this problem [15]. Some academic achievements focused on passenger route choice behaviors and characteristics both in hubs and network. Surveys about quality service, adequate informing, quality of vehicles, line routes, and timetables were carried out [16-19].

Passenger routing in line planning and timetabling. Line planning and timetabling depends on passenger flow routing. The typical method of line planning is based on the line pool. Lines in the pool are selected according to the shortest routes. The shortest routes are selected as passenger flow routes based on maximum direct passengers. Claessens presented a mathematical programming model to solve the allocation of passenger lines [20]. This problem was based on maximizing the number of direct travelers. Schöbel focused more on line planning. He found a set of paths for operating lines while aiming at minimizing transfers [21-22]. He used the Dantzig-Wolfe decomposition algorithm to solve the model. The sub-problem could be solved on the basis of shortest routes. Huiling Fu applied the line planning method from Schöbel to the Chinese HSR network to design a line plan considering cost-oriented and customer-oriented objectives [23-24].

In this work, we present a new approach for determining the transportation organization mode of an HSR network. We investigate the transportation organization mode via passenger flow routing in highspeed railway networks with respect to minimum total operation costs. The problem is solved through two-stages. First, given the railway infrastructure with the accompanying stations and passenger volumes between main OD pairs, the model determined operating cost-minimizing passenger flow routes. Then, the optimal results combining with route distances and line features are discussed to define the transportation organization mode of different transportation corridors.

\section{BASIC HYPOTHESES}

These hypotheses are made to depict passenger routing problems more logically and closer to reality. Cyclic annular railway can be avoided according to hypothesis 1 . To describe the difference of passenger routes in an operation period more logically, hypothesis 2 was constructed. Hypothesis 3 is put forward to explain the determination of passenger flow for passenger routing.

1) The physical network is established based on cities, choosing one station per city. However, two or more stations in one city which cannot connect with each other via railway are included. Cyclic annular railway is avoided in this way.

Beijing South (L1) and Beijing (L3) belong to the city of Beijing, and two independent nodes are set up (Figure 6). Tianjin has three stations which can connect by lines in the Tianjin hub. Only one node is set up in this city.

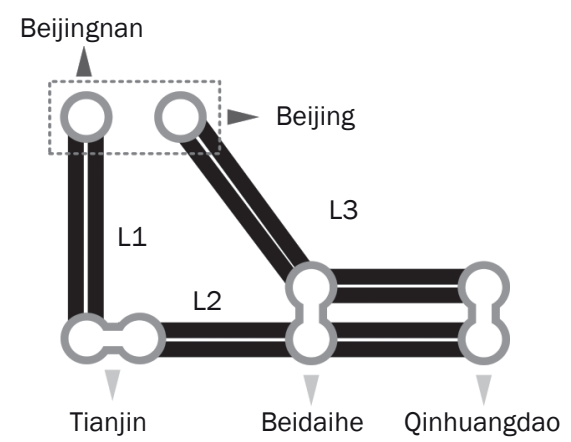

Figure 6 - An example of establishing a physical network 
2) The construction cost and rolling stock cost are not considered because the costs are apportioned over a long operation period.

3) Passenger demand is divided into several pairs of nodes for cities with two or more stations, because the demand data of all pairs of nodes indicates the demand of two cities. As Figure 6 shows, the demand between Beijing and Qinhuangdao is averaged between Beijingnan-Qinhuangdao and Beijing-Qinhuangdao.

\section{RESEARCH RESULTS AND PRESENTATION OF METHODS}

A physical network is a finite, directed graph $P N=(N, E)$ with a node set $N$ representing cities, and an edge set $E$ which contains driving edges and transfer edges. For each node $n . P N$ is constructed based on L-space; it means that for each edge $\{u, v\}$ there is a direct line from node $u$ to station $v$. For each edge $\{u, v\}$ we assume the driving time $t_{u v}$ and the travel time differences between different lines $t_{u v}^{v}$ are known. The edge cost $c_{u v}$ is represented in three parts: driving cost, cost of travel time differences between different lines, and inter-line penalties per train.

Moreover, let $R \subseteq N \times N$ denote the set of all origin -destination pairs when $q_{i j}$ means the sum of direct passengers. OD pairs can be served through the shortest route from $i$ to $j$. The shortest route is calculated by Dijkstra's algorithm.

The definitions of main sets, parameters, and variables which are needed in the model are shown below (Table 1).

\subsection{Enterprise model process}

Two models (Table 2) are introduced to solve the passenger flow routing problem. M1 is established to solve maximum direct travelers based on the undirected graph, which only considers the number of connected lines for each node. The number of direct travelers is used in M2. The objective of M2 is minimum operation cost, while considering nodes capacity, edges capacity, and direct travelers. The solutions for paired nodes, direct routes, and total cost are found.

Table 1 - The definition of sets, parameters, and variables

\begin{tabular}{|c|c|}
\hline \multirow{5}{*}{ Sets } & $\begin{array}{l}R: \text { set of OD pairs, all origin-destination pairs are contained } \\
V: \text { set of demand of all origin-destination pairs }\end{array}$ \\
\hline & $\begin{array}{l}K_{i}, K_{j}: \text { the number of nodes } i \text { and } j \text { connected with } \\
N_{R_{i j}}: \text { set of nodes of the route } R_{i j}\end{array}$ \\
\hline & $K_{i}^{u p}, K_{i}^{d n}:$ the number of nodes $i$ connected with upside and downside \\
\hline & $K_{j}^{u p}, K_{j}^{d n}:$ the number of nodes $j$ connected with upside and downside \\
\hline & $B_{e}, B_{n}:$ the bound of capacity for each node and edge \\
\hline \multirow{7}{*}{ Parameters } & $q_{i j}:$ direct passengers that can be served from $i$ to $j$ through shortest routes \\
\hline & $c_{i j}$ : the operating cost from $i$ to $j$ through shortest routes per train \\
\hline & $\begin{array}{l}y_{i j}^{e}: \text { if the shortest route from } i \text { to } j \text { contains edge } e \text { or not } \\
z_{i j}^{n:} \text { if the shortest route from } i \text { to } j \text { contains node } n \text { or not }\end{array}$ \\
\hline & $\begin{array}{l}b_{i j}^{e} \text { : if the route is chosen for } i, j \text { pair \& the route contains edge } e \text { or not } \\
w_{i j}^{n} \text { : if the route is chosen for } i, j \text { pair \& the route contains node } n \text { or not }\end{array}$ \\
\hline & $L:$ allowed number of trains, 490 people per train \\
\hline & $\theta:$ the proportion of direct passenger \\
\hline & $M:$ the most number of direct passenger (solved by M1) \\
\hline Variables & $x_{i j}$ : if $i$ and $j$ are paired or not, $x_{i j} \in\{0,1\}$ \\
\hline
\end{tabular}

Table 2 - The distinction of M1 and M2

\begin{tabular}{||l|l|l||}
\hline \multicolumn{1}{|c|}{ Model } & \multicolumn{1}{|c||}{ M1 } & \multicolumn{1}{|c||}{ M2 } \\
\hline \hline Network & Undirected & Directed \\
\hline Objective & Max. direct travelers & Min. operation cost \\
\hline Constraints & a. The number of connected lines & $\begin{array}{l}\text { a. The number of connected lines } \\
\text { b. Nodes capacity } \\
\text { c. Edges capacity } \\
\text { d. Direct travelers }\end{array}$ \\
\hline Results & $\begin{array}{l}\text { a. Paired nodes } \\
\text { b. Undirected routes } \\
\text { c. The number of direct travelers }\end{array}$ & $\begin{array}{l}\text { a. Paired nodes } \\
\text { b. Directed routes } \\
\text { c. Total cost }\end{array}$ \\
\hline
\end{tabular}




\subsection{M1 for maximum direct travelers}

To solve the passenger flow routing problem, the basic model was constructed [13]. Passenger flow routing with maximum direct travelers is presented. The M1 will pair nodes and select routes for maximum direct travelers based on the undirected graph. M1 objective $\max Q=\sum_{i \in P N} \sum_{j \in P N} q_{i j} \cdot x_{i j}$

$$
\begin{aligned}
\text { s.t. } & \sum_{j \in P N, i \neq j} x_{i j} \leq K_{i}, \quad \forall i, j \in P N \\
& \sum_{i \in P N, i \neq j} x_{i j} \leq K_{j}, \quad \forall i, j \in N P \\
& X_{i j}\left\{\begin{array}{ll}
1 & \text { if } i \text { and } j \text { are paired } \\
0 & \text { if } i \text { and } j \text { are not paired }
\end{array} \forall i, j \in P N\right. \\
& q_{i j}>0 \quad \forall i, j \in P N
\end{aligned}
$$

Constraints 1 and 2 make sure that the number of routes through any node is not above the number of lines which the node connects. The variables $x_{i j} \in\{0,1\}$ in Constraint 3 are set to be 1 if and only if $i$ and $j$ are paired. Then Constraint 4 takes the passenger volume into account, which is greater than 0 . The objective function we use is customer-oriented: we sum up the passenger volume $\sum_{i \in P N} \sum_{j \in P N} q_{i j} \cdot x_{i j}$ of a shortest route from $i$ to $j$, we maximize direct travelers. It should be noted that $q_{i j}$ means all demand can be transported through shortest route from $i$ to $j$.

The routes with more nodes and longer traveling distance will be selected if maximum direct travelers with efficient and rapid transportation cannot be guaranteed at the same time. This solution is not suitable for a large-scale HSR network. The basic model disregards restriction of carrying capacity in railway sections, which will lead to capacity imbalance and complex transportation organization.

\subsection{M2 for minimum total operation cost}

We propose the passenger flow routing model with minimum operating cost (M2) while ensuring the proportion of direct passengers and considering capacity constraints. We established some special terms for the following research. (1) Inter-line trains. Trains run on two or more lines with different operation speeds. (2) Travel time differences between different lines. Trains run on lines with different maximum operating speeds due to inter-line operations. The time difference indicates the difference between trains running on higher speed lines and those running on lower speed lines.
The travel time difference due to operating speed is used in a route which contains edges with different operating speeds.

For the route $A \rightarrow B \rightarrow C$, the travel time differences between different lines will occur for edge BC. Travel time differences between different lines can be calculated by the formula $t_{B C}^{V A C A N T}=t_{B C}^{200}-t_{B C}^{250}$ (Figure 7), meaning that a train can run at $250 \mathrm{~km} / \mathrm{h}$ regardless of the interline effect. Travel time differences between different lines of edge $\mathrm{BC}$ are between trains operating on $250 \mathrm{~km} / \mathrm{h}$ and $200 \mathrm{~km} / \mathrm{h}$ lines.

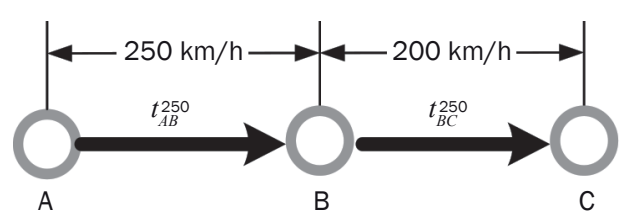

Figure 7 - An example of travel time differences between different lines

Constraints 1 and 2 in M1 will bring the new problem in a directed graph because constraints only restrict node-in and node-out. Passenger flow routes with the same direction on the same side for one node will be selected. Accordingly, the structure of the network needs to be amended. Four nodes are added into the nodes list for each station based on 2 directions of lines and 2 directions of nodes, node-in-up, node-indown, nodes-out-up, and nodes-out-down, respectively.

$A$ is the basic node form, $B$ is the form of node-in and node-out, then the form changes into a four-part node in M2 (C) as shown in Figure 8.

Constraints 5 and 6 are proposed to make sure that the number of train routes through any node belonging to the network is not higher than that of the lines which the node connects.

$$
\begin{gathered}
\text { s.t. } \sum_{j \in P N, i \neq j} x_{i j} \leq K_{i}^{u p}, \sum_{j \in P N, i \neq j} x_{i j} \leq K_{i}^{d n} \\
\sum_{i \in P N} x_{i j} \leq K_{i}^{u p}, \sum_{i \in P N, i \neq j} x_{i j} \leq K_{j}^{d n}
\end{gathered}
$$

Besides, Constraint 7 is put forward to guarantee a percentage of direct passengers because of the combination of direct and transfer transportation. The variable $M$ is the maximum direct passengers, which results from $\mathrm{M} 1$. $\theta$ is the proportion of direct passengers and the range of $\theta$ is 0 to 1 .

$$
\sum_{i \in P N} \sum_{j \in P N} x_{i j} \cdot q_{i j} \geq \theta \cdot M
$$

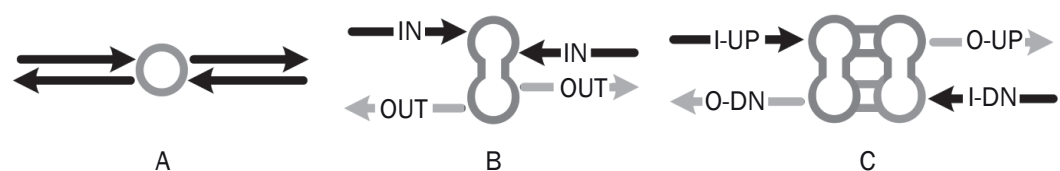

$$
\text { C }
$$

Figure 8 - The illustration of node expansion in $P N$ 
The operating cost per train contains route cost $c_{i j}^{t}$ cost of travel time differences between different lines $c_{i j}^{v}$, and penalty of inter-line $c_{i j}^{p}$ (Equation 8$)$. The route cost can be obtained by driving time multiplied by time cost because time cost is different at different operating speeds (Equation 9). For each route, the cost of travel time differences between different lines can be calculated by cost coefficient multiplied by travel time differences between different lines (Equation 10). Last, inter-line penalty is closely related to inter-line times (Equation 11).

$$
\begin{aligned}
& c_{i j}=c_{i j}^{t}+c_{i j}^{v}+c_{i j}^{p} \\
& c_{i j}^{t}=t_{i j}^{200} \cdot c^{200}+t_{i j}^{250} \cdot c^{250} \\
& c_{i j}^{v}=t_{i j}^{v} \cdot c^{v} \\
& c_{i j}^{p}=f_{i j} \cdot c^{p}
\end{aligned}
$$

The cost of different train types can be obtained based on the $\mathrm{CRH}$ EMU technology parameters (Table 3).

Table 3 - Main cost parameters values [25]

\begin{tabular}{||c|l|l||}
\hline \hline Parameter & \multicolumn{1}{|c||}{ Values } & \multicolumn{1}{|c||}{ Remarks } \\
\hline \hline$c^{200}$ & $341 € /$ hour & $\begin{array}{l}\text { Operating speed: } \\
200 \mathrm{~km} / \mathrm{h}\end{array}$ \\
\hline$c^{250}$ & $595 € /$ hour & $\begin{array}{l}\text { Operating speed: } \\
250 \mathrm{~km} / \mathrm{h} \text { and above }\end{array}$ \\
\hline$c^{v}$ & $2.8 \cdot 10^{-4} € /$ hour & $\begin{array}{l}\text { Compare with maximum } \\
\text { speed }\end{array}$ \\
\hline
\end{tabular}

M2 objective: $\min \sum_{i \in P_{N}} \sum_{j \in P N} x_{i j} \cdot \frac{q_{i j}}{L} \cdot c_{i j}$

$$
\begin{aligned}
& \text { s.t. } \sum_{i \in P N} \sum_{j \in P N} x_{i j} \cdot y_{i j}^{e} \cdot q_{i j} \leq B_{e} \\
& \sum_{i \in P N} \sum_{j \in P N} x_{i j} \cdot z_{i j}^{n} \cdot q_{i j} \leq B_{n} \\
& q_{i j} \geq 0, \quad B_{e}, B_{n} \geq 0 \\
& \theta \in(0,1] \\
& X_{i j}\left\{\begin{array}{l}
1 \text { if } i \text { and } j \text { are paired } \\
0 \text { if } i \text { and } j \text { are not paired }
\end{array} \forall i, j \in P N\right.
\end{aligned}
$$

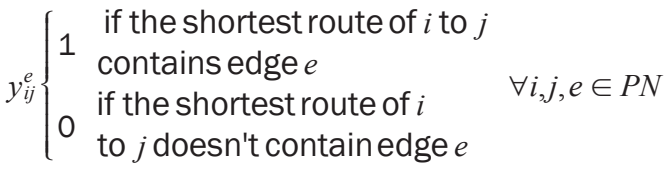

$z_{i j}^{n}\left\{\begin{array}{l}1 \begin{array}{l}\text { if the shortest route of } i \text { to } j \\ \text { contains node } n \\ \text { if the shortest route of } i \\ \text { to } j \text { doesn't contain node } n\end{array} \quad \forall i, j, n \in P N\end{array}\right.$

The boundaries of carrying capacity of edges and nodes are given in Constraints 12 and 13, respectively. Constraint 14 guarantees the passenger volume and capacity are greater than 0 . The variables $x_{i j} \in\{0,1\}$ in Constraint 16 are set to 1 if and only if $i$ and $j$ are paired, and the variables $z_{i j}^{e}, w_{i j}^{n} \in\{0,1\}$ in Constraints 17 and 18 are set to 1 if and only if edge $e$ or node $n$ is included in the shortest route from $i$ to $j$. We sum up the operating cost of a shortest path from $i$ to $j$, calculating the operating cost based on the number of operating trains, and we minimize the operating cost.

The introduced variables $z_{i j}^{e}, w_{i j}^{n}$ will increase the complexity of the algorithm due to capacity constraints. The capacity judgment is updated in each iteration according to passenger assignment. The calculation process will be complicated and calculation time will be longer.

Other extensions variables are introduced to reduce the complexity of the algorithm. Constraints 12 and 13 translate into Constraints 19 and 20 by introducing new variables $b_{i j}^{e}, w_{i j}^{n}$. The variables $b_{i j}^{e}, w_{i j}^{n}$ in Constraints 21 and 22 are set to 1 if $i$ and $j$ are paired, and the shortest route of $i$ to $j$ contains edge $e$ or contains node $n$.

$\sum_{i \in N} \sum_{j \in N} b_{i j}^{e} \cdot q_{i j} \leq B_{e}$

$\sum_{i \in N} \sum_{j \in N} w_{i j}^{n} \cdot q_{i j} \leq B_{n}$

$b_{i j}^{e}\left\{\begin{array}{c}0 \begin{array}{c}\text { if the route isn't chosen for } i, j \text { pair/ } \\ \text { the route doesn't contain edge } e \\ \text { if the route is chosen for } i, j \text { pair } \& \\ \text { the route contains edge } e\end{array}\end{array}\right.$

$w_{i j}^{n}\left\{\begin{array}{l}0 \begin{array}{l}\text { if the route isn't chosen for } i, j \text { pair/ } \\ \text { the route doesn't contain node } n \\ \text { if the route is chosen for } i, j \text { pair \& } \\ 1 \text { the route contains node } n\end{array}\end{array}\right.$

\subsection{Algorithm processes}

The algorithm processes are improved when new binary variables are applied. Passenger volume is assigned for the model after updating shortest routes.

A. Maximum direct volume for route $R_{i j}$ from $i$ to $j$ is calculated with the formula $V_{R_{i j}}=\sum_{i \neq j, j=i+1}^{j} q_{i j} . R_{i j}$ contains several nodes $N_{R_{i j}}$, and the passenger volume can be serviced for any two of these nodes paired in the direction of the route. The maximum of $\frac{N_{R_{i j}}\left(N_{R_{i j}}-1\right)}{2}$ passenger volumes of OD pairs will be summed. B. $V_{n-n+1}=\sum_{n \in N_{R i j}, i \leq n<j}^{N_{R_{i j}}} q_{n j}$ is used for passenger volume of each edge for each shortest route. $N_{R_{i j}}-1$ edges will be assigned for route $R_{i j}$.

C. We calculate the passenger volume of each node for each shortest route by formula

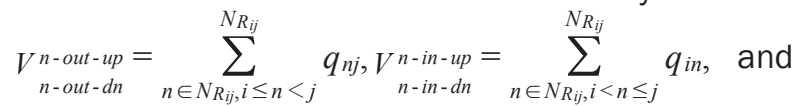
$2 N_{R_{i j}}$ nodes will be assigned for route $R_{i j}$. 


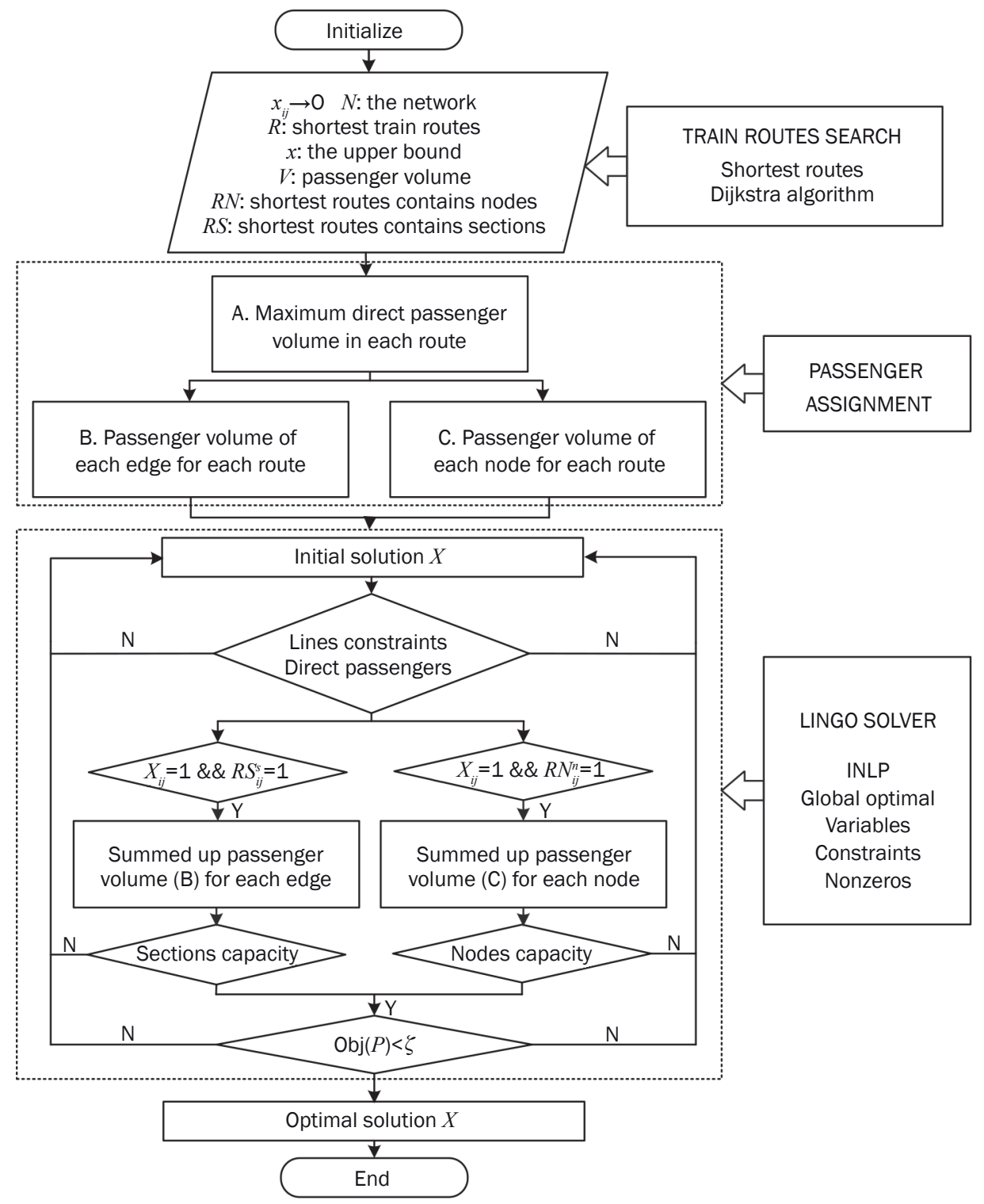

Figure 9 - The improved M2 algorithm process

The improved algorithm is shown in Figure 9. The initial solution $X$ is calculated by the Lingo solver, while line constraints and direct passengers are judged, but the judgment of node and section capacity constraints should be solved based on passenger assignment. The passenger volume of each edge (B) and passenger volume of each node $(C)$ for all selected routes are summed. If capacity constraints are not reached, a new solution will be applied, and the optimal solution will be found after many iterations.

A route with more passengers will be replaced by other routes if exceeding section capacity or nodes capacity limit in this iteration process. The process of iteration is the same as practical operation. The result shows a route which can provide a more direct service for OD pairs, and routes with less nodes are selected.

\section{CASE STUDY}

\subsection{Case descriptions}

Our approach is currently tested on a sub-network of the Northeast China railway network, which has seven high-speed railway lines (Table 4, Figure 10). The maximum operating speed is $300 \mathrm{~km} / \mathrm{h}$ and the minimum operating speed is $200 \mathrm{~km} / \mathrm{h}$. The given PN contains 76 expanded nodes, 36 edges, and 341 origin-destination pairs. The demand data for the passenger flow routing problem is given by the origin/destination matrix, specifying the number of travelers per day between all pairs of nodes.

Then a model with 49,104 variables and 36,667 constraints is built. The shortest route algorithm and passenger assignment on each route are implemented 
Table 4 - The basic information of PN

\begin{tabular}{||c|l|c|c||}
\hline \hline Numbers & \multicolumn{1}{|c|}{ Lines } & $\begin{array}{c}\text { Distance } \\
{[\mathrm{km}]}\end{array}$ & $\begin{array}{c}\text { Speed } \\
{[\mathrm{km} / \mathrm{h}]}\end{array}$ \\
\hline \hline 1 & Beijing-Tianjin & 120 & 250 \\
\hline 2 & Tianjin- Qinhuangdao & 350 & 250 \\
\hline 3 & Qinhuangdao-Shenyang & 404 & 200 \\
\hline 4 & Beijing-Qinhuangdao & 120 & 200 \\
\hline 5 & Harbin-Dalian & 921 & 300 \\
\hline 6 & Changchun-Hunchun & 456 & 200 \\
\hline 7 & Harbin- Qiqihar & 282 & 250 \\
\hline \hline
\end{tabular}

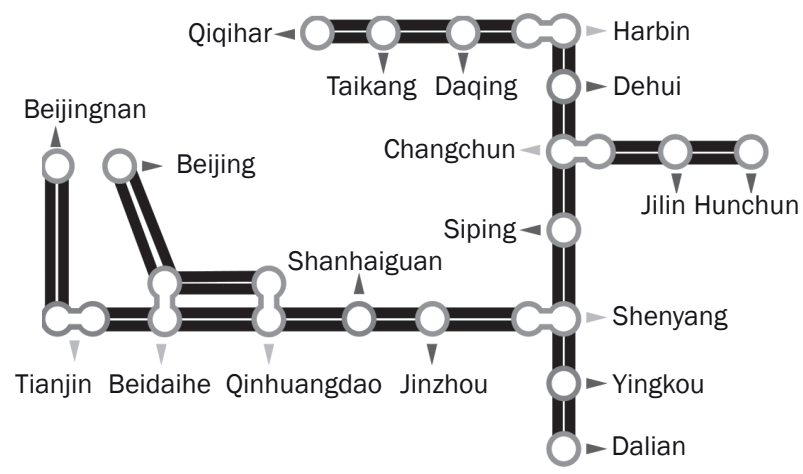

Figure 10 - The topological graph of the case

with C\#, and Lingo 11.0 is used to solve the non-linear programming model with a global optimal algorithm. The solver performs on a PC with a $3.2 \mathrm{GHz}$, Intel ${ }^{\mathrm{TM}}$ Core $^{\mathrm{TM}}$ i5-3470 processor and 16 GB of RAM running Windows 7 (64-bit).

\subsection{Results and discussion}

We discussed the model for different situations when parameters change.

The correlation between direct passengers and total cost

The direct passenger volume grows in inverse proportion to the increase of total cost. The more direct passenger demand is satisfied, the more cost it produces. The growth of total costs accelerates when the proportion of direct passengers is greater than $80 \%$. A rapid increase of total cost occurs when parameter $\theta$ is greater than $85 \%$ (Figure 11).

\section{The characteristics of routes}

The different train routes are optimized. The characteristics of the routes are summarized when parameter $\theta$ changes. The average nodes number, distance, and inter-line times increase with the proportion of direct passengers (Table 5). The rate of increase in these statistical values slows down when $\theta$ is greater than 90\% (Figure 12). More routes are selected when the

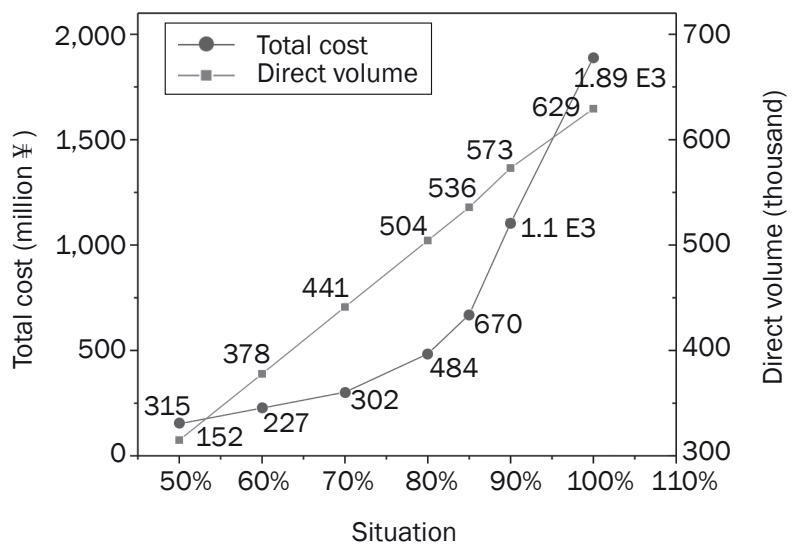

Figure 11 - The correlation between direct passenger and total cost

Table 5 - The statistical value of different situation

\begin{tabular}{|c|c|c|c|c||}
\hline Situation & $\begin{array}{c}\text { The } \\
\text { number } \\
\text { of routes }\end{array}$ & $\begin{array}{c}\text { Avg. } \\
\text { nodes }\end{array}$ & $\begin{array}{c}\text { Avg. } \\
\text { distance }\end{array}$ & $\begin{array}{c}\text { Avg. } \\
\text { inter-line } \\
\text { times }\end{array}$ \\
\hline \hline $100 \%$ & 9 & 5.000 & 622.444 & 0.667 \\
\hline $90 \%$ & 9 & 4.778 & 570.111 & 0.444 \\
\hline $85 \%$ & 11 & 4.545 & 476.545 & 0.364 \\
\hline $80 \%$ & 15 & 3.333 & 348.200 & 0.267 \\
\hline $70 \%$ & 21 & 2.550 & 236.667 & 0.190 \\
\hline $60 \%$ & 22 & 2.409 & 203.273 & 0.182 \\
\hline $50 \%$ & 20 & 2.350 & 178.400 & 0.250 \\
\hline \hline
\end{tabular}

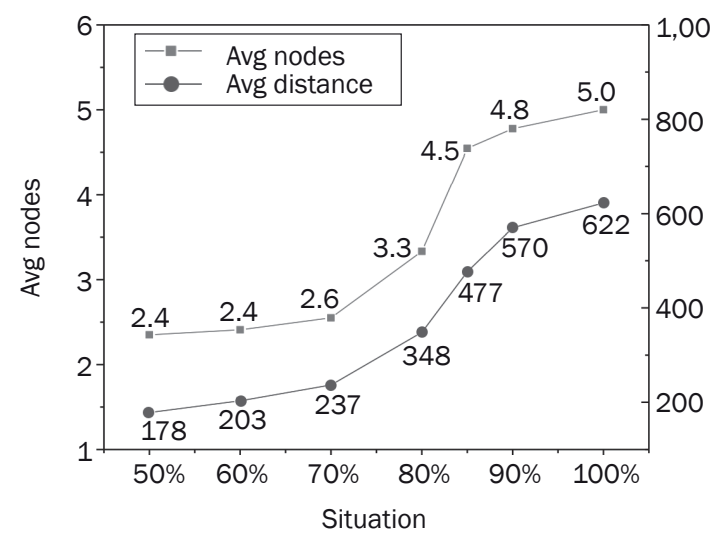

Figure 12 - The change of average nodes and average distance when parameter $\theta$ changed

proportion of direct passengers decreases because routes with more nodes can satisfy direct passenger volumes better.

\section{The transportation organization mode}

The longer distance routes are divided into several parts with the reducing proportion of direct passengers. The longest distance of routes is $1,565 \mathrm{~km}$ (Figure 13a). The total cost and difficulty of operation increase rapidly. The longest routes are from Beijing 


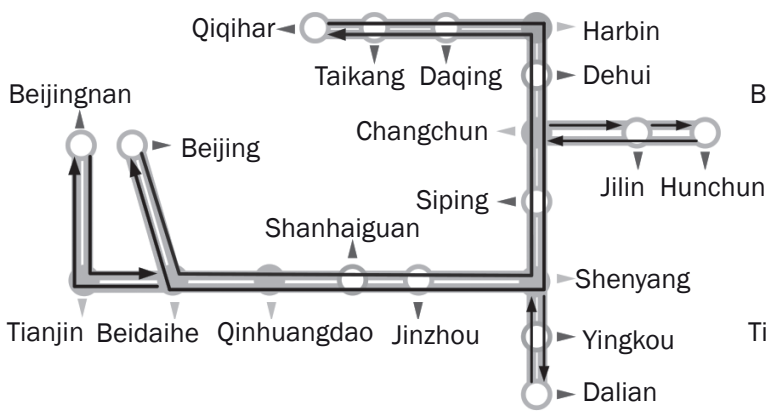

a) $100 \%$ direct passenger

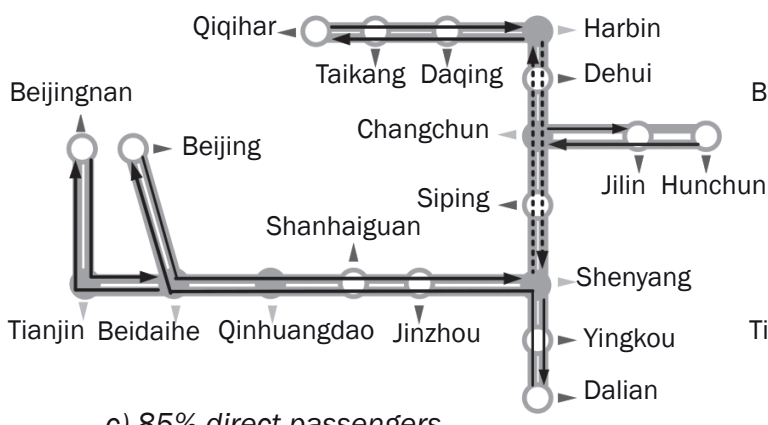

c) $85 \%$ direct passengers

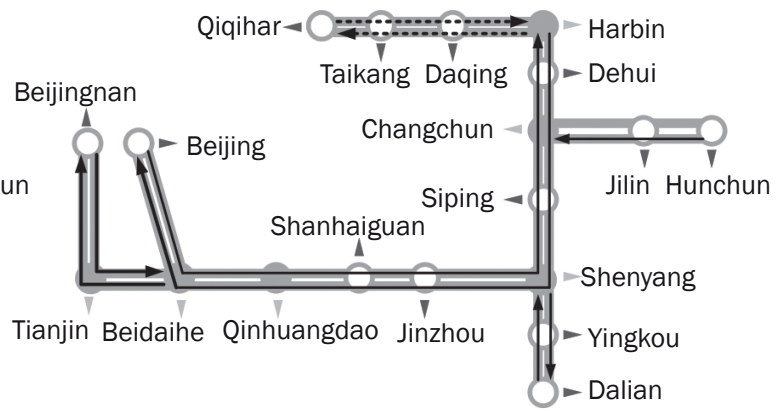

b) $90 \%$ direct passenger

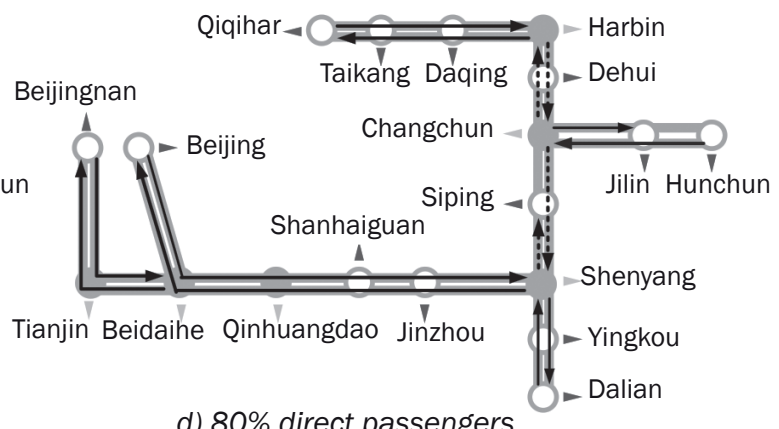

d) $80 \%$ direct passengers

Figure 13 - The illustration of paired nodes and routes in different situation

to Harbin or Harbin to Beijing (Figure 13b). The main change in Figure $13 \mathrm{c}$ is that the longest routes in Figure $13 \mathrm{~b}$ are divided into two parts. The route from Beijing to Dalian is the only longest route when parameter $\theta$ is $85 \%$ (Figure 13c). The optimal result shows an imbalance in the spatial distribution of passenger flow. The optimal result in Figure 13d is unrealistic because the influence of the Harbin-Dalian HSR is severely attenuated.

The transportation organization mode of the network in the case is demonstrated by the exiting line plan (Figure 14). It is similar to the optimal result of $90 \%$ direct passengers, but the total cost is $12.5 \%$ higher in comparison.
The optimal result using the second optimal model (M2) is confirmed as the result of making the transportation organization mode. The transportation organization modes of transport corridors are shown in Table 6. Intra-line or inter-line and periodic or non-periodic modes are determined based on route distances and line features. Inter-line trains will operate in corridors if routes are composed of several lines. Non-periodic mode will be adopted in corridors if inter-line routes have longer distances.

Passengers can finish trips only by taking one train when both origin and destination are in a result route. Passengers whose origin and destination is situated in different routes need a transfer to finish their trips based on results (Table 6).

Table 6 - The operation mode of main corridors in sub-network

\begin{tabular}{||l|c|c|c||}
\hline \multicolumn{1}{|c|}{ OD Pairs } & Distance $[\mathrm{km}]$ & Intra-line / Inter-line & Periodic/Non-periodic \\
\hline \hline Changchun-Jilin & 111 & Intra-line & Periodic \\
\hline Hunchun-Changchun & 471 & Intra-line & Periodic \\
\hline Dalian-Shenyang & 400 & Intra-line & Periodic \\
\hline Beijing-South-Beidaihe & 365 & Inter-line & Periodic \\
\hline Beidaihe-Beijing-South & 365 & Inter-line & Periodic \\
\hline Qiqihar-Harbin & 312 & Intra-line & Periodic \\
\hline Harbin-Qiqihar & 312 & Intra-line & Periodic/Non-periodic \\
\hline Shenyang-Harbin & 550 & Intra-line & Periodic/Non-periodic \\
\hline Harbin-Shenyang & 550 & Intra-line & Non-periodic \\
\hline Shenyang-Beijing & 703 & Inter-line & Non-periodic \\
\hline Beijing-Dalian & 1103 & Inter-line & \\
\hline
\end{tabular}




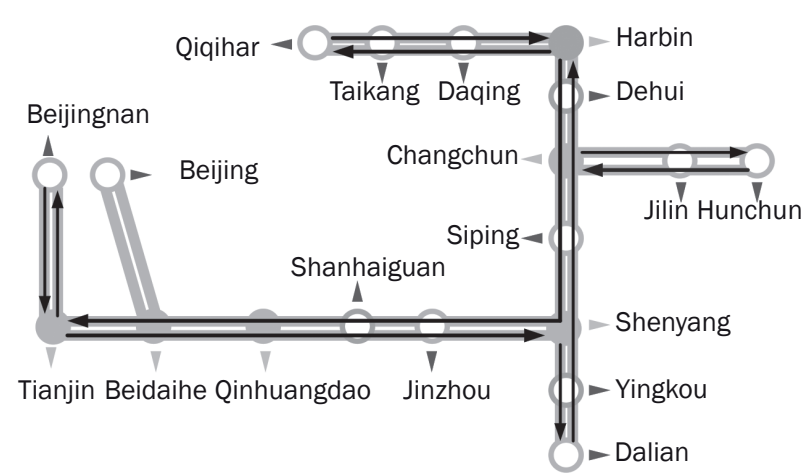

Figure 14 - The illustration of paired nodes and routes of the actual network

\section{CONCLUSIONS}

We developed an integer non-linear programming model for solving the passenger flow routing problem that minimizes the operating costs, including traveling cost, cost of travel time differences between different lines, and penalty for the inter-line. Two binary variables were introduced to simplify the flow diagrams algorithm. We discussed optimal results in different situations, and the transportation organization modes of a sub-network of the Northeast China railway network were determined.

Different transportation organization modes in network and unbalanced passenger flow are described in the passenger routing model. The method can be used to organize passenger flow in a large-scale HSR network at different development stages. We can determine the transportation organization mode of a region according to passenger routes.

On the one hand, the results provide a line pool reference which adapts to the complex operation environment for HSR network line planning. Network lines will be more effective considering different transportation organization modes, especially for multiple line speeds, unbalanced passenger flows, and different grades of stations.

On the other hand, research on passenger organization in hubs can be improved based on passenger routing models. Passenger organization in a hub containing multiple stations is also complex. A passenger routing model provides new ideas for the division of labor at the station within a hub.

\section{ACKNOWLEDGMENTS}

This work was supported by the "National Key R\&D Program of China" (2017YFB1200700). I extend my thanks to Professor Qi-yuan Peng for all his kindness and help.

王莹 ${ }^{1,2}$, 博士

邮箱: 18101349051@163.com

韩宝明3, 博士

邮箱: bmhan@bjtu.edu.cn
王家康 ${ }^{4}$, 博士

(通讯作者)

邮箱: wjksunny@126.com

1 西南交通大学交通运输与物流学院, 四川省成都市郫都 区犀安路999号

2 北京全路通信信号研究设计院集团有限公司，北京市丰 台区丰台科技园汽车博物馆南路1号院B座

3 交通运输学院, 北京交通大学, 北京市海淀区上园村3 号

4 中国民航管理干部学院, 北京市朝阳区花家地东路3号

基于不同运输模式的高速铁路网络客流路径优化模 型

\section{摘要}

为了适应大规模的高速铁路网络特征, 根据不同运输 组织模式进行合理的客流路径规划是提高高速铁路网络化 运营效率的重要措施。论文以旅客运输模式为基础, 提出 客流路径模型优化高速铁路网络的客流路径。模型中以运 营费用最小为研究目标, 运营费用包含出行成本、由于线 路运营速度不同产生的差异化运行时间费用和跨线惩罚费 用。为了更好适应有向图的场景对网络进行重构, 利用四 个节点表示一个车站, 四个节点包括进站上行、进站下 行、出站上行和出站下行。以该网络为基础提出整数非线 性化模型用以解决客流路径优化问题, 模型通过引入二进 制变量优化模型计算流程。构建了中国东北地区的高速铁 路网为案例对模型进行验证, 通过Ling011.0可得到最优 解, 根据得到客流量、运输距离和基础设施条件对网络的 运输组织模式进行探讨。

关键词

高速铁路; 运输计划; 运营模式; 客流路径; 整数非线性 规划模型

\section{REFERENCES}

[1] Feng F, Sun Q. Study on Transportation Organization for Shi-Tai Passenger Special Line. Railway Operation Technology. 2006;12(3): 5-7.

[2] Zhao P, Yang H. Study on Passenger Train Plans for Jing-Hu High-speed Railway, Journal of Beijing Jiaotong University. 2006;30(3): 5-9.

[3] Wang B, Yang H, Zhang ZH. The Research on the Train Operation Plan of the Beijing-Tianjin Intercity Railway Based on Periodic Train Diagram. Journal of the China Railway Society. 2007;29(2): 8-13.

[4] Claessens MT, van Dijk NM, Zwaneveld PJ. Cost Optimal Allocation of Rail Passenger Lines. European Journal of Operational Research. 1998;110: 474-489.

[5] Fu HL, Nie L, Yang H. Operation Plan for High-speed Train Based on European Rail Timetable. Journal of Beijing Jiaotong University. 2009;33(3): 45-51.

[6] Japan Ministry of Land. Infrastructure, transport and tourism railway board, date railway 2009. Tokyo, Japan: Wako Planet Press; 2009.

[7] Sun QP, Feng XS, Bian K. Operation and Organization Management of High-speed Railway in Japan. Journal of Transportation Systems Engineering and Information Technology. 2011;11(5): 11-16.

[8] Yu XK. Methods on Train Operation Mode of Highspeed Railway Passenger Train. PhD thesis. Chengdu, 
China: Southwest Jiaotong University; 2013.

[9] Zhou PF. Research on the Cross-line Passenger Flows Transportation Modes on High-speed Railways. Ph.D. thesis. Beijing, China: Beijing Jiaotong University; 2015.

[10] Tong L. Passenger flow assignment theory and meth ods of high-speed railway passenger transport service planning. Ph.D. thesis. Beijing, China: Beijing Jiaotong University; 2013.

[11] Tong L, Nie L, Fu HL. Research on Passenger Flow Assignment Method based on Complex Train Service Network. Journal of the China Railway Society. 2012;34(10): 7-15.

[12] Hu BS. Research on the technology of network construction based on train service plan and path search and the development of computer system. Ph.D. thesis. Beijing, China: Beijing Jiaotong University; 2010.

[13] Wang BH, He SW, Song R, et al. Stochastic Dependent-chance Programming Model and Hybrid Genetic Algorithm for Car Flow Routing Plan. Journal of the China Railway Society. 2007;4: 6-11.

[14] Wang S. Theory and method of Passenger Train Planning for Rapid Passenger Transport Network. Ph.D. thesis. Beijing, China: Beijing Jiaotong University; 2010.

[15] Jing Y, Zhang XC, Gan TT. A Cross-Entropy Method for Solving Passenger Flow Routing Problem. Advanced Materials Research. 2013;756-759: 3617-3621.

[16] Kim S, Shekhar S, Min M. Contraflow Transportation Network Reconfiguration for Evacuation Route Planning. IEEE Transactions on Knowledge \& Data Engineering. 2008;20(8): 1115-1129.
[17] Kesten AS, Öğüt KS. A New Passenger Oriented Performance Measurement Framework for Public Rail Transportation Systems. Promet - Traffic \& Transportation. 2014;26(4): 299-311.

[18] Chun-Ping HU, Mao BH, Zhu YT, et al. Optimization Method of Passenger Flow Routing Problem. Journal of Transportation Systems Engineering \& Information Technology. 2014;14(2): 158-161.

[19] Radnović B, Marić RM, Radnović V, et al. Marketing Research on Passenger Satisfaction with Public Transport Service in the City of Belgrade. Promet - Traffic \& Transportation. 2015;27(1): 47-57.

[20] Claessens MT, van Dijk NM, Zwaneveld PJ. Cost optimal allocation of rail passenger lines. European Journal of Operational Research. 1998;110(3): 474-489.

[21] Schöbel A, Scholl S. Line Planning with Minimal Transfers; 2005.

[22] Schöbel A. Customer-oriented Line Planning. PhD thesis. Göttingen, Germany: Georg-August University; 2006.

[23] Fu HL, Nie L, Yang H, et al. Research on the Method Optimization of Candidate-Train-Set Based Train Operation Plans for High-speed Railways. Journal of the China Railway Society. 2010;32(6): 1-8.

[24] Fu H, Nie L, Meng L, et al. A hierarchical line planning approach for a large-scale high-speed rail network: The China case. Transportation Research Part A: Policy \& Practice. 2015;75: 61-83.

[25] Zhou PF. Research on the Cross-line Passenger Flows Transportation Modes on High-speed Railways. PhD thesis. Beijing: Beijing Jiaotong University; 2015. 